\title{
USOS POLÍTICOS DE LA HISTORIA EN LA VENEZUELA DE CHÁVEZ Y MADURO*
}

\author{
Inés Quintero \\ Academia Nacional de la Historia, Venezuela
}

\begin{abstract}
RESUMEN: Esta conferencia da cuenta de cuáles han sido, en la Venezuela reciente, las principales manifestaciones del uso político de la historia, así como de qué manera se ha instrumentalizado el relato sobre el pasado con el fin de legitimar la revolución bolivariana y justificar así su ruptura con la tradición democrática del siglo XX.

Palabras Clave: Venezuela, instrumentalización del pasado, historiografía venezolana, revolución bolivariana, Hugo Chávez, Nicolás Maduro.
\end{abstract}

\section{POLITICAL USES OF HISTORY IN CHÁVEZ'S AND MADURO'S VENEZUELA}

ABSTRACT: This conference examines the main recent manifestations of the political use of history in Venezuela and the way a narrative of the past has been instrumentalized to legitimize the Bolivarian revolution and thus justify its break with the democratic tradition of the twentieth century.

Keywords: Venezuela, instrumentalization of the past, Venezuelan historiography, Bolivarian revolution, Hugo Chávez, Nicolás Maduro.

INÉs QUINTERO. Historiadora. Doctora en historia por la Universidad Central de Venezuela y miembro de número de la Academia Nacional de Historia, Venezuela. Email: ines.quintero@gmail.com.

* Versión revisada de la conferencia realizada en el Centro de Estudios Públicos, el 28 de agosto de 2018. 


\section{INTRODUCCIÓN}

L os usos políticos de la historia han sido objeto de estudio y reflexión entre los historiadores venezolanos hace ya bastante tiempo, especialmente respecto a la figura de Simón Bolívar. Es el caso, por ejemplo, del libro de Germán Carrera Damas, El culto a Bolivar, publicado en $1969,{ }^{1}$ y el trabajo de Luis Castro Leiva, De la patria boba a la teología bolivariana, ${ }^{2}$ referencias insoslayables para comprender el largo y complejo recorrido mediante el cual se llevó a cabo el proceso de deificación del héroe que convirtió a Bolívar en factor de la vida política, social y cultural de los venezolanos y en manadero e inspiración de las más diversas y contradictorias causas. Está también el estudio de Elías Pino Iturrieta Positivismo y gomecismo, ${ }^{3}$ en el cual se analiza la justificación de la dictadura del general Juan Vicente Gómez por parte de los más importantes voceros de esta corriente del pensamiento. Del mismo modo, muchas otras investigaciones de más reciente data atienden las muy diversas maneras de cómo se ha expresado el culto a Bolívar, en distintos momentos de nuestra historia, así como existen los análisis críticos respecto a las conmemoraciones y a la permanencia de los referentes de las historias patrias, sobre la Independencia, en el siglo $\mathrm{XX}^{4}$

Este interés y preocupación se ha mantenido y ha tenido un amplio desarrollo en estas últimas décadas, pues se ha buscado atender y analizar la exacerbación del uso político de la historia durante los

${ }^{1}$ Germán Carrera Damas, El culto a Bolívar. Esbozo para una historia de las ideas en Venezuela (Caracas: Ediciones de la Biblioteca de la Universidad Central de Venezuela, 1969). A partir de entonces, se han publicado numerosas ediciones.

${ }^{2}$ Luis Castro Leiva, De la patria boba a la teología bolivariana. Ensayos de historia intelectual (Caracas: Monte Ávila Editores Latinoamericana, 1987). Publicado nuevamente como parte de las Obras completas del autor, por la Universidad Católica Andrés Bello y la Fundación Empresas Polar, 2005-2009. Se pueden consultar en http://bibliofep.fundacionempresaspolar.org/publicaciones/libros/luiscastro-leiva-obras-i-y-ii/.

${ }^{3}$ Elías Pino Iturrieta, Positivismo y gomecismo (Caracas: Facultad de Humanidades y Educación, Instituto de Estudios Hispanoamericanos, 1978). Se hizo una nueva edición por Editorial Alfa, 2016.

${ }^{4}$ Inés Quintero, coordinadora, El relato invariable. Independencia, mito y nación (Caracas: Editorial Alfa, 2011). 
gobiernos de Hugo Chávez y Nicolás Maduro. Los libros de Manuel Caballero —Revolución, reacción y falsificación, Por qué no soy bolivariano y Contra la abolición de la historia - ${ }^{5}$ el estudio de Elías Pino Iturrieta, El divino Bolivar; 6 otra obra más reciente de Carrera Damas, El bolivarianismo-militarismo, una ideología de reemplazo; $;^{7}$ así como numerosos artículos y ensayos publicados en obras colectivas, revistas especializadas y números monográficos dan cuenta de la diversidad de reflexiones críticas elaboradas por historiadores y profesionales de otras disciplinas, cuyo propósito ha sido examinar el alcance y significación que ha tenido el uso del pasado con fines políticos en la historia reciente de los venezolanos. ${ }^{8}$

El tema también ha ocupado a historiadores fuera de Venezuela: es el caso Frédérique Langue, autora de numerosos artículos publicados en revistas latinoamericanas y europeas, en los cuales analiza la abusiva instrumentalización de la historia como recurso de legitimación política

5 Manuel Caballero, Revolución, reacción y falsificación (Caracas: Alfadil Ediciones, 2002); Por qué no soy bolivariano. Una reflexión antipatriótica (Caracas: Alfadil Ediciones, 2006); Contra la abolición de la Historia (Caracas: Editorial Alfa, 2008).

${ }^{6}$ Elías Pino Iturrieta, El divino Bolivar (Caracas: Alfadil Ediciones, 2006).

${ }^{7}$ Germán Carrera Damas, El bolivarianismo-militarismo, una ideología de reemplazo (Caracas: Editorial Alfa, 2011).

${ }^{8} \mathrm{Al}$ respecto, pueden verse los trabajos de Ángel Almarza, "Dos siglos de historia mal contadas", en El relato invariable. Independencia, mito y nación, coordinado por Inés Quintero (Caracas: Editorial Alfa, 2011), 125-154; Rogelio Altez, "Independencia, mito genésico y memoria esclerotizada", en El relato invariable. Independencia, mito y nación, coordinado por Inés Quintero (Caracas: Editorial Alfa, 2011), 19-56; Nelly Arenas y Luis Gómez Calcaño, El imaginario redentor de la Revolución de Octubre a la Quinta República (Caracas: Cendes, UCV, 2000); Luis Alberto Buttó y José Alberto Olivar, Entre el ardid y la epopeya. Uso y abuso de la simbología en el imaginario chavista (Caracas: Fundación Negro sobre Blanco Grupo Editorial, 2018); Alejandro Gómez, "El papel de los intelectuales en la Venezuela de Hugo Chávez: los historiadores a la palestra pública", L'Ordinaire Latino-Américain 202 (2005): 83-94; María Elena González de Luca, "Historia, usos, mitos, demonios y magia revolucionaria", Revista Venezolana de Economía y Ciencias Sociales 11, n. ${ }^{\circ} 2$ (2005): 159-186; Inés Quintero, "Bolívar dictador, Bolívar revolucionario", en El Bolivar de Marx (Caracas: Editorial Alfa, 2007), 27-47; Tomás Straka, La épica del desencanto. Bolivarianismo, historiografía y politica (Caracas: Editorial Alfa, 2009). Ana Teresa Torres, La herencia de la tribu. Del mito de la Independencia a la Revolución Bolivariana (Caracas: Editorial Alfa, 2009). 
durante el chavismo; ${ }^{9}$ o el caso del muy completo libro El poder y el delirio, de Enrique Krauze, quien, luego de visitar Venezuela en 2008, realizar numerosas entrevistas y analizar de cerca la dimensión del problema, llegó a la conclusión de que en la Venezuela chavista se "ha desvirtuado, falsificado y utilizado la historia a extremos pocas veces vistos". ${ }^{10}$

Los usos políticos de la historia constituyen, sin duda, importante materia de reflexión y debate en la historiografía contemporánea, lo cual, además, trasciende los espacios de discusión estrictamente académicos, convirtiéndose inevitablemente en asunto de discusión pública: el caso de Venezuela es un buen ejemplo. Considérese también lo que ha ocurrido en España con la muy polémica Ley de memoria histórica aprobada en 2007, que en la actualidad sigue generando posiciones encontradas, poniendo de manifiesto la envergadura y complejidad del problema, fundamentalmente cuando está de por medio la intervención del Estado. ${ }^{11}$ Se trata de un debate

\footnotetext{
${ }^{9}$ Algunos artículos recientes de la Dra. Frédérique Langue son los siguientes: "La Independencia de Venezuela. Una historia mitificada y un paradigma heroico", Anuario de Estudios Americanos 66, n. ${ }^{\circ} 2$ (2009): 245-276; "De panteones cívicos e imaginarios políticos. Los usos del pasado en la revolución bolivariana”, en Hugo Chávez: una década en el poder, editado por Francesca Ramos Pismataro, Carlos A. Romero y Hugo Ramírez Arcos (Bogotá: Universidad del Rosario/Centro de Estudios Políticos e Internacionales/Observatorio de Venezuela, 2010), 761-781; “'Levántate Simón, que no es tiempo de morir'. Reinvención del Libertador e historia oficial en Venezuela”, Araucaria Revista Iberoamericana de Filosofia, Política y Humanidades 25 (2011) — http://www-en.us.es/araucaria/nro25/nro25.htm-; "Usos del pasado y guerra de las memorias en la Venezuela de la 'Segunda Independencia'", Polis 34 (2013), http://polis. revues.org/8953/.

${ }^{10}$ Enrique Krauze, El poder y el delirio (Caracas: Editorial Alfa, 2008), 19.

${ }^{11}$ En marzo pasado, un grupo de historiadores e intelectuales españoles de diferentes posiciones políticas suscribieron un documento titulado Manifiesto por la historia y la libertad. El primer párrafo dice: "No se puede imponer por una ley un único relato de la historia, ya que ninguna ley debe o puede variar los hechos históricos. No se debe borrar por una ley la cultura, el sentimiento ni la memoria de un pueblo, y menos aún por razones ideológicas. Ninguna razón moral, ni derecho subyacente, puede primar sobre la analítica verdad de los hechos en las circunstancias del tiempo y lugar en que estos se produjeron. La interpretación de unos hechos, cualquiera que estos sean, no puede ceder a ninguna manipulación política partidista. Legislar sobre la historia o contra la historia es, simplemente, un signo de totalitarismo. Y es antidemocrático y liberticida". Ver https://www.abc. es/espana/abci-mas-200-historiadores-investigadores-firman-manifiesto-historia-ylibertad-201803142110_noticia.html/.
} 
también presente en Chile, ${ }^{12}$ así como en otros países de América Latina.

Se trata, por tanto, de un tema inescapable en la agenda historiográfica del presente, que compromete de manera directa el ejercicio profesional de la historia, especialmente frente a la posibilidad de que su orientación y contenidos estén sujetos o controlados por el Estado, con fines distintos a los del ejercicio crítico y plural que debe primar en la elaboración del conocimiento histórico.

En este sentido, recurro a las prudentes y elocuentes palabras de un historiador alemán que, sin duda, experimentó una de las mayores operaciones de manipulación y control totalitario, el del nacionalsocialismo de Adolfo Hitler. Me refiero al Dr. Georg Iggers, a quien tuve la oportunidad de conocer personalmente aquí en Santiago de Chile, en el año 2012, cuando Iván Jaksic, con el empeño y disciplina que lo caracterizan, tradujo, editó y presentó el importante libro de Iggers $L a$ historiografía del siglo XX. Desde la objetividad cientifica al desafio posmoderno. ${ }^{13}$

${ }^{12}$ Sobre el debate en torno a los usos políticos de la historia en el caso de Chile, durante y después de la dictadura de Augusto Pinochet, es ilustrativo el ensayo de Julio Pinto "Cien años de propuestas y combates. La historiografía chilena del siglo XX", especialmente cuando se refiere a "Historiar en dictadura 1973-1999", $\mathrm{y}$, luego, al detenerse sobre el período siguiente que lleva por título "La batalla de la memoria". En Cien años de propuestas y combates. La historiografía chilena del siglo XX, de Julio Pinto y María Luna Argudín, 21-114 (México: Universidad Autónoma Metropolitana, 2006). También resulta de interés el manifiesto de los historiadores chilenos, de enero de 1999, publicado en distintos medios impresos, a fin de dar respuesta crítica a la visión histórica expuesta por Pinochet en su Carta a los chilenos, luego de que fue detenido en el Reino Unido, del mismo modo que a las interpretaciones elaboradas por el historiador Gonzalo Vial, sobre la historia reciente de Chile. En el último párrafo de este documento los historiadores fijan posición sobre las consecuencias que tienen para la sociedad tergiversar la historia con fines políticos. El texto es como sigue: "La historia no es sólo pasado, sino también, y principalmente, presente y futuro. La historia es proyección. Es la construcción social de la realidad futura. El más importante de los derechos humanos consiste en respetar la capacidad de los ciudadanos para producir por sí mismos la realidad futura que necesitan. No reconocer ese derecho, usurpar o adulterar ese derecho es imponer, por sobre todo, no la verdad sino la mentira histórica. Es vaciar la verdadera reserva moral de la humanidad". Está reproducido en la misma obra de Julio Pinto y María Luna Argudín, 455-465.

${ }^{13}$ Santiago: FCE, 2012. 
En el año 2000 le correspondió a Georg Iggers, en compañía de François Bédarida, abrir y presidir el panel que, bajo el título "Usos y abusos de la historia. La responsabilidad del historiador, pasado y presente", se llevó a cabo en el Congreso Internacional de Ciencias Históricas celebrado en Oslo. Entre sus observaciones al debate hizo las siguientes precisiones:

La suposición subyacente al panel es que los enfoques honestos a la historia son posibles y que el ethos profesional del historiador lo llama a resistir las interpretaciones erróneas del pasado. Sin embargo, la relación entre los usos y abusos de la historia es muy compleja. El uso indebido sugiere que el pasado es instrumentalizado y distorsionado por motivos políticos o de otro tipo. También significa que hay un pasado real que no debe ser distorsionado..$^{14}$

Es pues desde esta posición de "resistencia" que quisiera compartir con ustedes algunas de las expresiones más representativas de lo que han sido las distorsiones e instrumentalizaciones del pasado que han tenido lugar en la Venezuela de Hugo Chávez y de Nicolás Maduro.

\section{LA HISTORIA AL SERVICIO DE LA REVOLUCIÓN}

Desde los inicios de su actuación pública, hubo varios aspectos que estuvieron presentes en el discurso de Chávez: la reiterativa utilización de la figura de Simón Bolívar como guía e inspiración de su accionar político y su determinación de conducir un proceso revolucionario que permitiese romper de un todo con el pasado, para fijar un antes y un después en la historia de Venezuela.

El momento político así lo demandaba. Después de cuarenta años de "punto fijismo", como calificó recurrentemente al período de la democracia representativa, era imperativo llevar adelante el proceso de refundación de la república, para lo cual resultaba imprescindible convocar una Asamblea Nacional Constituyente, responsable de sancionar una constitución que fijase las bases de este nuevo pacto político.

${ }^{14}$ Georg Iggers, "Introductory remarks to the panel The Uses and Misuses of History", en Congreso Oslo 2000. Disponible en http://www.oslo2000.uio.no/program/papers/m3a/m3-iggers.pdf/. Consultado el 8 de enero de 2018. 
Estas ideas fueron explicadas de manera exhaustiva y sin variaciones en numerosas entrevistas, actos y presentaciones públicas, durante su campaña electoral para la presidencia de la república y están sintetizadas en la Agenda alternativa bolivariana. ${ }^{15}$

El 6 de diciembre de 1998, como es sabido, Hugo Chávez ganó las elecciones presidenciales con el 56,27 por ciento de los votos válidos. Su más cercano contendor obtuvo el 39,9 por ciento de los votos y la abstención fue del 36,5 por ciento. El 2 de febrero se realizó el acto de toma de posesión en el Congreso Nacional, en el cual, al momento de prestar su juramento ${ }^{16} \mathrm{y}$ en su discurso ante ambas cámaras, insistió en su determinación de llevar a cabo una revolución que, bajo la guía de Simón Bolívar, permitiese acabar con el "modelo político nefasto" de los últimos cuarenta años y dar inicio a la refundación de la república. ${ }^{17}$

${ }^{15}$ Hugo Chávez Frías, Agenda alternativa bolivariana (Caracas: sin editorial, 1996). Reimpreso por el Ministerio del Poder Popular para la Comunicación y la Información (Ediciones del Correo del Orinoco, 2014), también conocido con el nombre de "El libro rojo".

${ }^{16} \mathrm{El}$ texto completo de su juramento ante el Congreso de la República fue el siguiente: "Juro ante Dios, ante la patria y ante mi pueblo, sobre esta moribunda Constitución, que haré cumplir e impulsaré las transformaciones democráticas necesarias para que la república nueva tenga una carta magna adecuada a los tiempos".

17 Varios fragmentos seleccionados del discurso de toma de posesión del Presidente Hugo Chávez dejan ver el sentido y alcance de la propuesta revolucionaria y la necesidad de reunir la Asamblea Nacional Constituyente: "Eso no tiene otro nombre que una revolución. Terminando el siglo XX y comenzando el siglo XXI venezolano aquí se desató una verdadera revolución, señores, y yo tengo la certeza de que nosotros le vamos a dar cauce pacífico, que nosotros le vamos a dar cauce democrático a esa revolución que anda desatada por todas partes (...). Tenemos que revolucionarnos, incluso nosotros mismos, es hora de oír a Bolívar de nuevo y ahora es cuando los venezolanos van a oírme hablar de Bolívar, porque ése es el faro (...). No hay marcha atrás en la revolución política que tenemos que impulsar y que claman las calles del pueblo de toda esta tierra de Bolívar. (...) (La constitución) tiene que morir y junto a ella el modelo político nefasto al que dio nacimiento en estos últimos cuarenta años. Eso tiene que morir. Va a morir, señores. Acéptenlo todos y es necesario que muera, pero claro que, al mismo tiempo, es necesario que nazca otro modelo (...). La Constituyente no es una panacea, nunca la planteamos así. Tiene un objetivo fundamental como es la transformación de las bases del Estado y la creación de una nueva república, la refundación de la república, la relegitimación de la democracia. Ese es el objetivo". Hugo Chávez Frías, "Discurso de toma de posesión ante el Congreso de la República", Caracas 2 de febrero de 1999. Disponible en http://todochavez.gob.ve/todochavez/3013-toma-de-posesion-delcomandante-presidente-hugo-rafael-chavez-frias/. 
Ya no se trataba de una oferta electoral de quien había sido candidato presidencial, sino de una decisión política que empezaría a ser ejecutada por quien acababa de juramentarse como Jefe del Estado. Ese mismo día aprobó el Decreto $n$. $^{\circ} 3$ de su gobierno, convocando un referéndum consultivo para que el "pueblo" se pronunciara respecto a la realización de la Asamblea Nacional Constituyente.

La idea de ruptura histórica constituyó desde el primer momento una pieza clave del discurso de Chávez, a fin de justificar y hacer valer la propuesta de un cambio revolucionario. La revolución que se ofrecía al país necesitaba, por tanto, ejecutar acciones que permitiesen, efectivamente, producir una transformación que tuviese consecuencias prácticas y visibles para el conjunto de la sociedad, independientemente de las controversias, rechazos o disputas que hubiese al respecto. En la ejecución de esta resolución política fue determinante, como ya se dijo, apoyarse en el ideario de Simón Bolívar como soporte incuestionable y legitimador de la mudanza que se quería llevar a cabo.

La prioridad política del Presidente Chávez, inmediatamente después de tomar posesión de su alta investidura, fue lograr, a como diera lugar y cuanto antes, la realización de la Constituyente, el mecanismo idóneo que permitiría otorgarle soporte legal y legitimidad política a su proyecto revolucionario. Si bien el camino hacia la Constituyente no estuvo exento de dificultades - ya que hubo un intenso debate acerca de la legalidad y constitucionalidad de su convocatoria mientras que se introdujeron numerosos reparos ante la Corte Suprema de Justicia-, ninguna de estas acciones logró interrumpir el proceso. ${ }^{18}$

El 25 de abril de 1999 se realizó el referéndum consultivo que resultó a favor de efectuar una Constituyente, el 25 de julio se realizaron las elecciones y el 3 de agosto se instaló la Asamblea. La composición era absolutamente ventajosa para el Polo Patriótico, alianza de partidos que apoyó la candidatura de Chávez y que se presentó a las elecciones

18 Tanto la convocatoria al referéndum como la realización de una Asamblea Nacional Constituyente fueron objeto de fuertes polémicas, referidas fundamentalmente a debatir si podía modificarse la Constitución de 1961, vigente para entonces, si no estaba contemplado en ella ninguno de estos mecanismos para su reforma o sustitución. Un buen resumen sobre este tema puede leerse en el artículo de Carlos García Soto “¿Cómo fue el proceso constituyente de 1999?”, disponible en http:// historico.prodavinci.com/blogs/como-fue-el-proceso-constituyente-de-1999-porcarlos-garcia-soto/. 
de la Constituyente con una lista única de candidatos. Esta alianza, con el 62 por ciento de los votos válidos, obtuvo el 95 por ciento de los diputados de la Asamblea, la suma de 125 miembros; el resto de los diputados, un total de 6 , constituía la bancada de la oposición.

Fue éste el escenario ante el cual el Presidente Chávez presentó sus Ideas fundamentales para la Constitución Bolivariana de la V República. En su discurso ante los miembros de la Constituyente expuso los argumentos que le daban soporte a su propuesta de refundación de la república, de lo cual formaba parte cambiarle el nombre al país por el de República Bolivariana de Venezuela, con el propósito de que estuviese en correspondencia con el proceso de ruptura que se estaba llevando a cabo. Estuvo claro, en el contenido de la exposición, su determinación de dar comienzo a un nuevo momento de la historia de Venezuela, el de la revolución bolivariana, bajo la inspiración y guía de Simón Bolívar, tal como lo había expuesto en la campaña y en la toma de posesión. En este contexto tenía una importancia capital no solamente sancionar una carta magna que sentara las bases del nuevo pacto político, sino que su aprobación también estuviese acompañada de una resolución que dejase en evidencia la profundidad de la ruptura "revolucionaria" que se estaba llevando a cabo, y que tuviese consecuencias para todos los venezolanos. Fue ése el objetivo sustancial de promover el cambio de nombre del país. ${ }^{19}$

Al comenzar su intervención ante la Constituyente, Chávez recurrió al primer párrafo del discurso de Simón Bolívar en el acto de instalación del Congreso de Angostura, en 1819: "Dichoso el ciudadano que bajo el escudo de las armas de su mando convoca a la soberanía nacional para que ejerza su voluntad absoluta". ${ }^{20}$

Esta mención a Bolívar no es casual, y deja ver con absoluta transparencia la resolución por parte del Presidente Chávez de establecer una

${ }^{19}$ El tema del cambio de nombre del país fue desarrollado por mí en "La historia al servicio del poder: Venezuela de República a Bolivariana”, discurso de incorporación como académica corresponsal de la Academia Mexicana de la Historia, correspondiente de la Real Madrid, Ciudad de México, 6 de febrero de 2018. Disponible en http://www.anhvenezuela.org.ve/sites/default/files/1/discurso_iq_academia_mexicana_2018.pdf/.

20 "Discurso del ciudadano Hugo Rafael Chávez Frías, Presidente de la República", Diario de Debates, 5 de agosto de 1999. Disponible en http://todochavez. gob.ve/todochavez/3482-intervencion-del-comandante-presidente-hugo-chavezfrias-en-la-asamblea-nacional-constituyente/. 
relación de continuidad entre la acción del Libertador y el proceso revolucionario que, bajo su conducción, se estaba iniciando en Venezuela. Si en 1819 Bolívar convocó a la soberanía a fin de presentar su propuesta constitucional para Colombia, en 1999, Hugo Chávez, siguiendo los pasos de Bolívar, convocaba igualmente a la soberanía nacional para dar a conocer su propuesta de Constitución Bolivariana:

Ciento ochenta años después, en esta Caracas bolivariana, yo me atrevo a decir, parodiando al Padre y trayendo su inspiración eterna: Glorioso el pueblo que rompiendo las cadenas de cuatro décadas y levantándose sobre sus cenizas y empuñando con firmeza la espada de su razón, cabalga de nuevo el potro brioso de la revolución. ${ }^{21}$

La referencia a las cuatro décadas tampoco es casual. Había llegado el momento de acabar con el sistema político de la democracia representativa cuyos conductores eran los responsables de la hecatombe que se vivía en Venezuela en 1998 y, al mismo tiempo, realizar un acto ineludible de reparación histórica, pendiente desde 1830, cuando la oligarquía de entonces - la oligarquía conservadora — "echó atrás los postulados de la revolución y produjo un siglo XIX lleno de violencia, de estertores intestinos que de verdad disolvieron la nación, disolvieron la unidad del pueblo y disolvieron la República".22

Un fragmento del discurso es absolutamente claro de la manera cómo se interpreta la traición a Bolívar y se plantea la imperiosa necesidad de reparar el agravio cometido:

Hoy, así como aquella Cuarta República nació sobre la traición a Bolívar y a la revolución de Independencia, así como esa Cuarta República nació al amparo del balazo de Berruecos y a la traición, así como esa Cuarta República nació con los aplausos de la oligarquía conservadora, así como esa Cuarta República nació con el último aliento de Santa Marta, hoy le corresponde ahora morir a la Cuarta República con el aleteo del cóndor que volvió volando de las pasadas edades (...). Hoy muere la Cuarta República y se levanta la República Bolivariana. ${ }^{23}$

\footnotetext{
21 "Discurso del ciudadano Hugo Chávez Frías", Diario de Debates.

22 Ibídem.

${ }^{23}$ Ibídem.
} 
De acuerdo a la argumentación expuesta por el Presidente, desde la muerte de Bolívar en 1830 hasta 1999, se había permanecido en una especie de vacío histórico, carente de realizaciones, durante el cual todo había sido oprobio, violencia, destrucción y cuyas funestas manifestaciones podían advertirse en el pasado inmediato. La refundación de la República Bolivariana permitiría, entonces, reparar la traición cometida contra el Padre de la Patria, recuperar su legado interrumpido y ponerlo en práctica bajo la dirección de Hugo Chávez Frías. A Chávez, de acuerdo a sus propias palabras, le correspondería ser el "último Presidente de la IV República y el primer Presidente de la V República, de la República Bolivariana que vuelve". ${ }^{24}$

Dos meses después de su exposición ante los diputados de la Constituyente, en la segunda semana de octubre, se debatió el proyecto constitucional de la nueva república y se rechazó el cambio de nombre para el país: sólo obtuvo 38 votos.

El Presidente Chávez no estuvo dispuesto a aceptar este revés. En los días previos a que se discutiera por segunda vez el contenido de la constitución para su sanción final, convocó a una reunión en la residencia presidencial, a la cual asistieron la junta directiva de la Asamblea Nacional Constituyente y los representantes de los partidos que formaban parte de la alianza del Polo Patriótico. Entre los propósitos de la reunión estuvo exigirles la aprobación del nuevo nombre para el país. Dos días después, el 12 de noviembre, se llevó a cabo la segunda discusión, en esta ocasión se aprobó el cambio de nombre, seguido de aplausos.

No quedan dudas respecto al efecto que tuvo la intervención del Presidente para lograr este resultado. Y es que para el proyecto político de Chávez resultaba imperativo que la ruptura histórica, postulada de manera discursiva, quedara consagrada constitucionalmente en la nueva carta magna de la República Bolivariana de Venezuela. ${ }^{25}$ La propuesta

${ }^{24}$ Ibídem.

${ }^{25}$ El proyecto constitucional que entregó el Presidente Hugo Chávez a la consideración de la Asamblea Nacional Constituyente incorporó en el Capítulo II, "De la República", varios artículos sin numeración en los cuales se contempla el nuevo nombre: "Venezuela se declara República Bolivariana, irrevocablemente libre e independiente, y fundamenta su patrimonio moral, así como los valores de libertad, igualdad, justicia y paz internacional, en la doctrina de Simón Bolívar, el Libertador. Artículo.- El gobierno de la República Bolivariana de Venezuela es democrático, social, responsable, participativo y alternativo". Comandante Hugo Chávez Frías, Presidente de la República de Venezuela, Ideas fundamentales para la Constitución Bolivariana de la V República (Caracas: 1999), 5. 
de refundar la república tenía en el cambio de nombre un recurso simbólico fundamental, ese cambio representaba el referente icónico de la ruptura revolucionaria que se estaba llevando a cabo. A partir de entonces, no quedaba la menor duda de que había un antes y un después en la historia de Venezuela, marcado por el inicio de la revolución bolivariana. De allí el especial empeño en conseguir su aprobación. El artículo primero de la constitución quedó redactado en los términos siguientes:

Artículo $1^{\circ}$ : La República Bolivariana de Venezuela es irrevocablemente libre e independiente y fundamenta su patrimonio moral y sus valores de libertad, igualdad, justicia y paz internacional en la doctrina de Simón Bolívar, el Libertador. Son derechos irrenunciables de la Nación la independencia, la libertad, la soberanía, la inmunidad, la integridad territorial y la autodeterminación nacional. ${ }^{26}$

Poco tiempo después, el Municipio Libertador también cambió su nombre a Municipio Bolivariano Libertador, del mismo modo lo hicieron algunos Estados por iniciativa de sus gobernadores, los cuales comenzaron a llamarse Estado Bolivariano de Miranda, de Guárico, de Vargas, de Nueva Esparta y así sucesivamente. Se utilizó también el adjetivo bolivariano para nombrar los programas sociales del gobierno: el Plan Bolívar 2000; se crearon los círculos bolivarianos como instancias de organización del pueblo y más adelante se llegó al exceso de bautizar como bolivarianos algunos rubros de la producción agrícola nacional. Hoy la Guardia Nacional, la Policía Nacional y muchísimas otras instituciones del Estado son Bolivarianas. ${ }^{27}$ De esta manera, y desde los inicios del gobierno de Chávez, se estableció la identificación y sujeción de los programas, organismos e instituciones del Estado a los objetivos políticos de la revolución bolivariana, bajo la conducción del Jefe del Estado y recurriendo al manto proyector y legitimador del Padre de la Patria.

26 Ver página 1 de la Constitución de la República Bolivariana de Venezuela, aprobada el 17 de noviembre de 1999. Como puede apreciarse, el texto es casi idéntico al presentado por el Presidente Chávez en sus Ideas fundamentales para la Constitución Bolivariana de la V República (ver nota 27).

27 Esta generalización del adjetivo "bolivariano" es desarrollada por Pino Iturrieta, El divino Bolívar, en el capítulo titulado "La multiplicación de la insania", 231-241. 
La idea de la refundación de la república, del mismo modo que el cambio de nombre, así como los argumentos sobre los cuales Chávez fundamentó su propuesta fueron fuertemente criticados por historiadores e intelectuales, y hubo un amplio debate por la prensa, a través de comunicados y en diferentes escenarios académicos y políticos. Entre los argumentos centrales expuestos por quienes hicieron consideraciones críticas frente a esta visión maniquea y utilitaria de la historia, estuvo que no podía desconocerse la totalidad del proceso histórico venezolano privilegiando exclusivamente el período de la independencia, y mucho menos establecer constitucionalmente el evidente anacronismo que representaba considerar que los planteamientos elaborados por Simón Bolívar, en 1811 o en 1826, podían servirle a la república en el siglo XXI. Resultaba, además, totalmente absurdo atar el nombre de un país a una de sus figuras históricas, como era el caso de Simón Bolívar. $^{28}$ No hubo caso. La respuesta del Presidente en cadena nacional y a través de su programa de radio fue de descalificación y rechazo. ${ }^{29}$

La refundación de la república y el cambio de nombre quedaron consagrados de manera definitiva, luego de la aprobación de la Constitución de la República Bolivariana de Venezuela en un referéndum nacional realizado el 15 de diciembre de 1999 en medio de fuertes

${ }^{28}$ La Academia Nacional de la Historia debatió el tema y dirigió una carta pública al presidente de la Asamblea Nacional Constituyente, advirtiendo la inconveniencia de la medida. Los argumentos están recogidos en el Acta de la Junta General, 11 de noviembre de 1999, Libro de Actas de la Junta General de la Academia Nacional de la Historia, año 1999, Archivo de la Academia Nacional de la Historia. Se publicaron numerosos artículos por la prensa escritos por miembros de la Academia y otros historiadores, al igual que por otros intelectuales venezolanos: Elías Pino Iturrieta, "La tropelía de la República Bolivariana", El Universal, 16 de noviembre de 1999; Manuel Caballero, "Los enemigos de Bolívar", El Universal, 22 de noviembre de 1999 ("borrar 480 años de la historia de la formación de la Nación venezolana para sustituirla por los veinte años donde actuó de manera sobresaliente un líder convertido luego en semidiós"); Simón Alberto Consalvi, "Sin tranquilidad en el sepulcro", y Alberto Barrera Tyszka, "El evangelio según Chávez", ambos en El Nacional, 21 de noviembre de 1999. El periódico El Globo publicó un largo reportaje al abogado Román Duque Corredor, el 15 de noviembre, sobre el mismo tema bajo el título "Irrespetuoso capricho la República Bolivariana". Hubo también un comunicado titulado "Juntos por el NO", en el cual se rechaza "el uso utilitario del nombre del Libertador para convertirlo en parte de una operación política oportunista", El Universal, 1 de diciembre de 1999.

29 "El Presidente contraataca a través de su programa radial", El Nacional, 15 de noviembre de 1999. 
aguaceros torrenciales, los cuales ocasionaron una terrible tragedia en la parte central de la costa norte del país y especialmente en el Estado Vargas, considerada por los expertos como una de las peores catástrofes de la historia de Venezuela. ${ }^{30}$

Se instaura así una práctica política mediante la cual una instancia de representación popular, como la Asamblea Nacional Constituyente, se coloca al servicio del Jefe del Estado, a fin de dar respuesta satisfactoria a las demandas de su proyecto político, en cuya formulación y justificación ocupa un lugar de primer orden la utilización de la historia, especialmente la figura de Bolívar, como factor de legitimación política y como recurso de afirmación discursiva del proceso revolucionario que se pretende instaurar.

\section{LOS SÍMBOLOS PATRIOS DE LA REVOLUCIÓN BOLIVARIANA}

Esta misma práctica estará presente al finalizar el año 2005, esta vez con el propósito de cambiar los símbolos patrios, a fin de que estuviesen en armonía con los objetivos de la revolución bolivariana. De esta manera se busca reafirmar la ruptura iniciada desde 1999 al cambiarle el nombre al país, incluyendo en este desiderátum revolucionario a dos de las más icónicas representaciones de la nación y del Estado: la bandera y el escudo.

La significación que tienen estos símbolos es parte de una larga historia que se remonta a los orígenes de la experiencia republicana. Sobre este tema, el historiador Armando Martínez Garnica, en su ensayo "La nacionalización de los símbolos patrios", ${ }^{31}$ explica que, tanto en Venezuela como en Colombia, del mismo modo que en los demás países que surgieron del desmantelamiento del imperio espa-

${ }^{30}$ El impacto de la tragedia y sus devastadoras consecuencias han sido analizados por el investigador Rogelio Altez. Algunos títulos al respecto son: "Historia sin memoria: la cotidiana recurrencia de eventos desastrosos en el Estado VargasVenezuela", Revista Geográfica Venezolana, n. ${ }^{\circ}$ especial (2005): 313-342; “Más allá del desastre. Reproducción de la vulnerabilidad en el Estado Vargas (Venezuela)", Cahiers des Amériques Latines 65, n. ${ }^{\circ} 3$ (2010): 123-143.

31 Armando Martínez Garnica, "La nacionalización de los símbolos patrios", en La República de Colombia 1819-1830. El legado de una experiencia nacional, trabajo del postdoctorado en historia (Universidad Andina Simón Bolívar. Quito, 2015. Inédito). 
ñol, el nacimiento de los distintos Estados nacionales se vio acompañado de un amplio y complejo proceso de diferenciaciones en lo constitucional, en lo político, territorial, económico, cultural, social, educativo, etcétera. De este esfuerzo de diferenciación participaron las formas de representación de la nación, de lo cual fueron expresión fundamental los símbolos patrios, piezas claves, entre muchas otras, del largo trayecto de construcción y consolidación de este proyecto, cuya finalidad fue crear y afianzar, mediante su uso y difusión, el sentido de pertenencia y de común identificación entre los ciudadanos. Es ése el sentido histórico, y al mismo tiempo simbólico, que tuvieron, y siguen teniendo, los llamados símbolos patrios, así como la sanción de las leyes que establecen su utilización pública o castigan su transgresión.

Fue pues, precisamente, este icónico referente simbólico de la nación y del Estado el que, por iniciativa del Presidente Chávez, fue sometido a revisión a fin de incorporar un conjunto de modificaciones que permitiesen ajustarlo al proyecto político de la revolución bolivariana, apoyándose, una vez más, en la palabra de Simón Bolívar y utilizando la absoluta mayoría con la cual contaba en la Asamblea Nacional (AN). Vale la pena puntualizar que, en las elecciones parlamentarias del 4 de diciembre del 2005, los partidos de oposición decidieron no presentarse a la consulta electoral, lo cual tuvo como resultado que la AN estuviese compuesta, en su totalidad, por diputados del Polo Patriótico.

El Presidente Chávez hizo pública su propuesta de cambiar la bandera y el escudo en su programa de televisión Aló Presidente, transmitido en vivo el 20 de noviembre de 2005. En relación con la bandera, su planteamiento fue que debía incluirse una octava estrella y, respecto al escudo, su proposición fue que se modificara la dirección del caballo para que estuviese galopando hacia la izquierda.

La idea de incluir una octava estrella tenía su origen en un decreto de Simón Bolívar dictado en Guayana ese mismo día, el 20 de noviembre pero de 1817 , a fin de agregar otra estrella a las siete que ya tenía la bandera, con el objetivo de reconocer la incorporación de Guayana a la causa de la independencia, luego del triunfo del ejército libertador sobre esta provincia, la que se había mantenido fiel a la monarquía desde 1810 . De esta manera, tal como insistió Chávez por televisión, finalmente se 
haría efectiva la decisión de Bolívar al momento de liberar a Guayana, 188 años después y coincidiendo con la revolución bolivariana. ${ }^{32}$

La proposición de cambiar la dirección del caballo, para que estuviese galopando hacia la izquierda, tuvo su origen en una conversación doméstica que sostuvo con su hija menor, Rosinés, cuando ésta le preguntó por qué el caballo del escudo estaba mirando hacia atrás, como si estuviese frenado. Procurando ofrecerle una respuesta a su hija constató que había otros escudos en los cuales el caballo aparecía corriendo hacia la izquierda, al galope; en consecuencia, luego de hacer un recorrido por la historia de los símbolos patrios, desde el siglo XIX hasta el presente, propuso ante las cámaras la posibilidad de que una comisión estudiara el asunto ".... a ver si es que la patria del siglo XXI pudiera retomar símbolos originales y traerlos de nuevo a la palestra". ${ }^{33}$

32 "Aquí tenemos cosas pendientes, bueno, la octava estrella a la bandera nacional, será el año que viene porque hay que cambiar la ley, hay que hacer una nueva ley, yo voto a favor, no me corresponde a mí tomar la decisión, eso le corresponde a la muy soberana Asamblea Nacional. (...) Bien, pero tenemos pendiente entonces para el próximo año será ¿no? lo de la octava estrella, Simón Bolívar decretó aquí en Guayana, porque ustedes saben que las siete estrellas de nuestra linda y heroica bandera recoge las siete provincias que se sumaron al movimiento o las siete provincias que había en la Capitanía General de Venezuela, luego cuando liberan a Guayana entonces Bolívar dice: 'Vamos a incorporar la octava estrella', por tanto es la estrella de Bolívar, es la estrella bolivariana, le falta a la bandera la octava estrella”. Fragmento de la exposición hecha por Hugo Chávez en el programa Aló Presidente, episodio 240, Puerto Ordaz, 20 de noviembre del 2005.

${ }^{33}$ En esta ocasión las palabras de Chávez fueron las siguientes: "Bueno, miren yo les iba a comentar lo de Rosinés. Rosinés me dijo: 'Papá, ¿por qué ese caballo mira hacia atrás?'. Es un caballo que, no sé, es un caballo en posición extraña y ustedes saben que los códigos ideológicos son sembrados muchas veces en los símbolos patrios y quedan en el subconsciente y a veces nadie se da cuenta de manera conciente (sic), pero Rosinés sí me dijo: 'Papá, y ese caballo ¿por qué mira hacia atrás y además parece que está frenado?'. Me puse yo a buscar y resulta que hay otros escudos que han sido de Venezuela donde el caballo está corriendo hacia la izquierda, galopando, pero galopando, un galope; este caballo no está galopando, está parado ahí; es más, parece frenado y está mirando hacia atrás, está mirando hacia atrás, su cuerpo hacia la derecha y él como que busca hacia la izquierda". Y más adelante manifestó: "Ese caballo no es el caballo del escudo nacional del siglo XIX, cuando nació el escudo de Venezuela, lo cambiaron, lo cambiaron; y entonces me parece justo que nosotros lo cambiemos otra vez, y lo pongamos como estaba un caballo galopante, un caballo que se ve que va volando en el viento, como la patria". En Aló Presidente, episodio 240, 20 de noviembre de 2005. 
A la semana siguiente, frente a las numerosas reacciones contrarias a la proposición del Presidente, las cuales fueron calificadas por él como "estupideces" promovidas por la "oligarquía apátrida", reiteró Chávez su resolución de cambiar los símbolos y le planteó a la Asamblea Nacional que lo incorporase a la agenda de discusión, luego de su instalación al año siguiente. En esta oportunidad, además de volver sobre la octava estrella, puso especial empeño en el cambio de dirección del caballo. En el escudo, a lo largo de la historia, según afirmó el Presidente, ha habido un caballo reaccionario y antibolivariano y otro indómito y bolivariano. Lo que se buscaba con la reforma era volver al caballo bolivariano y descartar el caballo reaccionario, así de sencillo. ${ }^{34}$

El 6 de enero de 2006, una comisión de la Asamblea Nacional visitó al Presidente a fin de notificarle la instalación del poder legislativo. La ocasión fue propicia para que Chávez les solicitara que evaluaran los dos cambios propuestos en su programa televisivo. ${ }^{35}$ En los días siguientes, la Comisión Permanente de Política Interior, Justicia, Derechos Humanos y Garantías Constitucionales, presidida por la diputada Cilia Flores, esposa del presidente de la Asamblea Nacional, diputado Nicolás Maduro, elaboró la exposición de motivos que permitiese avanzar en la reforma de la Ley de Bandera, Escudo en Himnos Nacionales. La propuesta recogió en su totalidad las sugerencias hechas por el Presidente, argumentando que se trataba de invocar el "espíritu bolivariano" que había servido de "inspiración para la refundación de la República" ${ }^{36}$ Esto en el caso de la bandera. En relación con el caballo,

34 “Aparece aquí en 1836, el escudo de 1836 es donde aparece el caballo con el cuello invertido, estamos hablando de 1836, el caballo de la Gran Colombia lo invierten. Ahora, es el caballo antibolivariano. El caballo de la Gran Colombia, el que va cabalgando a la izquierda, libre, es el caballo bolivariano, el otro es el antibolivariano, es el caballo de la cuarta república, es el caballo que se devuelve. Chivo que se devuelve, se esnuca (sic). Es un caballo que se devuelve, es un caballo no indómito. ¿Quién puede pensar...? Bueno, repito, esto es un análisis, ya les voy a mostrar algo impresionante. Pero miren, el escudo actual, díganme ustedes si esta figura del caballo, si esto refleja un caballo indómito, ése es un caballo frenado, es un caballo que alguien lo frenó y lo puso a mirar al pasado, lo puso a mirar hacia atrás, eso no es un caballo indómito, ése es el caballo que devolvió el sueño de Bolívar, es decir allí hay un símbolo reaccionario". Aló Presidente, episodio 241, 27 de noviembre de 2005.

${ }^{35}$ El Nacional, 7 de enero de 2006, A-2.

${ }^{36}$ Ver la sesión del 11 de enero de 2006 sobre la "Exposición de motivos de la reforma de la ley bandera, escudo e himno nacionales", en Diario de Debates, enero-febrero de 2006, tomo I, 253. 
modificar su posición, para que cabalgase hacia la izquierda, brioso y al galope, simbolizaba "el espíritu libertario, indómito y soberano del pueblo venezolano y su gesta independentista". ${ }^{37}$

Luego de presentar el proyecto ante la Asamblea, el 17 de enero fue convocado un grupo de profesores universitarios, todos ellos egresados de la Escuela de Historia de la Universidad Central de Venezuela y comprometidos con el proyecto político del gobierno, a fin de que expusieran las razones y argumentos que le daban sustento a la mudanza. $^{38}$ Todos, sin excepción, expusieron que era necesario y oportuno introducir los cambios propuestos, descartaron que fuese una decisión caprichosa y arbitraria del Presidente y afirmaron que la decisión se justificaba para que los símbolos patrios estuviesen en sintonía con la refundación de la república y con el proyecto de la revolución bolivariana. "El carácter de transformación que están viviendo la sociedad y las instituciones del Estado venezolano obliga a los representantes del Poder soberano a modificar la Ley que establece el régimen de los Símbolos Patrios", 39 fue el argumento expuesto por uno de los invitados. Mientras que otro se encargó de insistir en el alcance revolucionario que tenía la propuesta: "Toda revolución lleva aparejados cambios en las actitudes y en los comportamientos de la sociedad, también de cambios en los símbolos que identifican esa sociedad". ${ }^{40}$

Se ofrecieron, igualmente, consideraciones puntuales sobre la conveniencia de hacer valer el reconocimiento hecho por Bolívar a la provincia de Guayana por su incorporación a la independencia, en 1817, y también se insistió en la pertinencia simbólica que constituía modificar la imagen del caballo para que estuviese galopando briosamente hacia la izquierda.

Hubo un intenso debate por la prensa y en numerosos espacios públicos. La Academia Nacional de la Historia, al ser consultada, se pronunció rechazando la propuesta y destacando sus inconveniencias,

${ }^{37}$ Ibídem.

${ }^{38}$ Los historiadores convocados fueron: Pedro Calzadilla y Luis Felipe Pellicer, miembros de la Dirección General de Investigación y Desarrollo Legislativo de la Asamblea Nacional; Germán Yépez, rector suplente del Consejo Nacional Electoral, y Héctor Acosta, integrante de la Comisión Metropolitana de Historia de la Alcaldía Metropolitana, en tiempos del alcalde Juan Barreto.

${ }^{39}$ Asamblea Nacional, Diario de Debates, 17 de enero de 2006, 250.

${ }^{40}$ Asamblea Nacional, ibídem, 251. 
así como la ausencia de motivaciones y argumentos que le diesen sustento a la mudanza; ${ }^{41}$ del mismo modo hubo otros pronunciamientos y reflexiones críticas, los cuales se manifestaron incluso en el seno de la Asamblea Nacional. También se realizaron asambleas, foros, encuentros de consulta y diversos actos políticos de apoyo al cambio planteado por el Presidente.

A pesar de las opiniones y juicios contrarios a la mudanza, la ley fue aprobaba en segunda discusión, en los primeros días de marzo, con la finalidad de que pudiese ser refrendada por el Ejecutivo y publicada en la Gaceta Oficial para la celebración, el 12 de marzo del 2006, del bicentenario del día en que Francisco de Miranda izara, por primera vez, el pabellón tricolor, durante su fallida expedición libertaria de 1806.

Ese día, el Presidente Chávez izó la nueva bandera. La ocasión fue oportuna para dirigirse al país en cadena nacional y reiterar la significación que tenían los cambios introducidos en los símbolos patrios, ya que, al reunirse el tricolor traído por Miranda y la octava estrella decretada por el Libertador, se había recuperado “el espíritu del proyecto libertario de Simón Bolívar y Francisco de Miranda". La octava estrella, representaba "la victoria y el futuro"; mientras que el caballo libre, brioso trotando hacia la izquierda representaba "el retorno de Bolívar". 42

Durante los actos conmemorativos, además de la ofrenda floral ante la tumba del Libertador, hubo un desfile cívicomilitar en el cual

${ }^{41}$ Ver el comunicado "La Academia Nacional de la Historia y los símbolos patrios", El Nacional, 11 de febrero de 2006. Dice: “1. Los símbolos patrios constituyen íconos de identificación de un Estado, y por tanto no deben ser alterados ni modificados sino en circunstancias históricas transcendentales y consolidadas en la vida de un país. La majestad de los símbolos debe inspirar la necesaria estabilidad del Estado como institución política que arropa a la totalidad de sus habitantes. Alrededor de los símbolos se aglutina el sentimiento que une a la población de un país para constituir y estructurar un Estado. // 2. Los cambios, cuando fueren necesarios, deben ser objeto de una amplia consulta, en especial entre organismos públicos y privados relacionados con el conocimiento de lo que dichos símbolos significan en el tejido institucional y en la conciencia ciudadana. // 3. Los cambios que se hagan sin responder a una sólida justificación contribuyen a desorientar, alterar y debilitar la cohesión que por necesidad requiere todo Estado".

42 "Chávez izó por primera vez la bandera nacional”, El Nacional, 13 de marzo de 2006, A-2. 
participaron más de 10 mil integrantes de las Fuerzas Armadas Nacionales con sus trajes de honor y cerca de 20 mil personas con franelas rojas en representación de las distintas misiones del gobierno, precedidos por un caballo blanco al galope en representación del "animal del nuevo escudo, que corre sin voltear la cabeza, símbolo de la libertad". ${ }^{43}$

Todas las argumentaciones expuestas por Chávez, por los diputados de la Asamblea Nacional y por quienes secundaron obsecuentemente la propuesta dejan ver que la motivación, que estuvo presente en el cambio de los símbolos patrios, fue eminentemente política, más allá de apoyarse o recurrir a la figura de Bolívar, en el caso de la bandera, o de hacer valer que en el pasado el caballo aparecía cabalgando hacia la izquierda. La ruptura histórica que constituía la refundación de la república demandaba la fijación de una nueva forma de representación de la nación, mediante el cambio de la bandera y el escudo que identificaban a la República Bolivariana de Venezuela.

Concluida esta etapa de afirmación de la revolución bolivariana se inicia lo que el Presidente Chávez llamó el socialismo del siglo XXI, en el cual seguirá ocupando lugar destacado el uso de la historia, con la finalidad de institucionalizar, desde el Estado, un relato único y monolítico sobre el pasado que sirva igualmente de soporte al proyecto político del primer mandatario.

\section{UN RELATO HISTÓRICO ÚNICO Y MONOLÍTICO}

Al finalizar el año 2006, concluido el primer período constitucional de Hugo Chávez Frías, hubo nuevas elecciones, en las cuales el resultado favoreció su reelección. En esta oportunidad, durante su campaña, anunció la instauración del "socialismo del siglo XXI", en el que Simón Bolívar también se convertía en guía e inspiración. ${ }^{44}$

${ }^{43}$ Ibídem.

${ }^{44}$ Hugo Chávez en Aló Presidente, del 15 de febrero de 2007: "Mi opinión es, legisladores, que el fundamento de nuestro sistema depende inmediata y exclusivamente de la igualdad establecida y practicada en Venezuela". Seguidamente afirmó que fueron palabras dichas por el Libertador mucho antes que Carlos Marx, Vladimir Lenin y Rosa Luxemburgo. "Pensamiento socialista", concluyó. "Que los hombres nacen - continuó la lectura - todos con derechos iguales a los bienes de la sociedad, está sancionado por la pluralidad de los sabios". Por unos momentos se detuvo para considerar que se trató de una postura que toma principios de Cristo, "otro gran socialista". 
Planteó así la necesidad de reunir, en un solo partido, las distintas organizaciones políticas que desde 1998 habían acompañado el proyecto político de la revolución bolivariana. El nombre propuesto inicialmente fue el Partido Socialista Único de Venezuela (PSUV), lo cual generó de inmediato reacciones encontradas por lo que representaba la propuesta de un partido único. Muy rápidamente se modificó y se planteó como Partido Socialista Unido de Venezuela.

En el acto de promoción y fundación del partido, una vez más, recurrió a Simón Bolívar para justificar la necesidad de la unión y el encuentro de los revolucionarios, citando varios textos del Libertador como la Carta de Jamaica: "Es la unión ciertamente lo que nos falta para completar la obra de nuestra regeneración; mas sin embargo, esa unión no nos vendrá por prodigios divinos, sino por efectos sensibles y esfuerzos bien dirigidos". Y en su última proclama: "Si mi muerte contribuye a que cesen los partidos y se consolide la unión yo bajaré tranquilo al sepulcro". Estas dos referencias de Bolívar, y otras más, le permitieron justificar la necesidad perentoria del PSUV: "Sigamos la palabra de Bolívar que sigue hablando desde la distancia, si no fundimos el alma nacional en un todo, si no fundimos el cuerpo nacional en un todo, el espíritu nacional en un todo, un nuevo coloniaje legaríamos a nuestros hijos y a nuestros nietos". ${ }^{45}$

Ese mismo día quedó constituido formalmente el PSUV bajo la dirección de Hugo Chávez, quien fue elegido como su presidente y fundador. En la actualidad el presidente del partido es Nicolás Maduro.

En este contexto de afirmación y conducción cada vez más centralizada y vertical del gobierno revolucionario, resulta fundamental la institucionalización desde el Estado de un relato único y monolítico sobre el pasado que sirva de justificación a la revolución. Ya no se trata exclusivamente de instaurar los recursos que simbolicen de manera inequívoca la ruptura histórica que se inicia con el gobierno de Chávez, sino de elaborar y difundir una versión única y uniforme de la historia de Venezuela, ajustada a la narrativa política de la revolución. Con ese fin, el 17 de octubre de 2007 se crea por decreto presidencial el Centro Nacional de Historia (CNH).

${ }^{45}$ Discurso de Hugo Chávez en el primer evento con propulsores del PSUV, y que tuvo lugar en Caracas, el 24 de marzo 2007. Ver http://todochavez.gob.ve/ todochavez/2585-primer-evento-con-propulsores-del-partido-socialista-unido-devenezuela-psuv/. 
El texto del decreto es inequívoco respecto a las funciones que le corresponde cumplir a este organismo adscrito al poder ejecutivo, como una institución perteneciente al Ministerio de Cultura. El decreto dice así:

CONSIDERANDO: Que la historia nacional constituye un bien irrenunciable del pueblo venezolano y uno de los pilares fundamentales de su identidad, donde se conjuga la visión de justicia social, de desarrollo humano integral, la soberanía y la independencia de la Nación.

Que es obligación del Estado Venezolano fomentar y desarrollar el conocimiento, investigación, conservación y divulgación del acervo histórico de la memoria tangible e intangible de los venezolanos.

Que el Estado Venezolano no cuenta con una institución especializada destinada a ejercer la rectoría de las acciones y políticas concernientes a la historia nacional y la memoria colectiva del pueblo venezolano.

Que el Estado Venezolano debe garantizar el derecho de las comunidades a participar en el reconocimiento, recolección, preservación, protección, transmisión y enriquecimiento de la memoria histórica de la Nación.

DECRETA:

Artículo $1^{\circ}$. Se autoriza la creación de una fundación del Estado, denominada "CENTRO NACIONAL DE HISTORIA", la cual estará adscrita al Ministerio del Poder Popular para la Cultura y tendrá como domicilio la ciudad de Caracas, pudiendo establecer oficinas y dependencias dentro y fuera del territorio de la República, previa autorización del Consejo Directivo y aprobación del órgano de adscripción.

Artículo $2^{\circ}$. El "CENTRO NACIONAL DE HISTORIA" tendrá por objeto ejercer la rectoría de las políticas tendentes al desarrollo de las acciones y actividades del Estado Venezolano, orientadas a la investigación, conservación, preservación y difusión de la historia nacional y de la memoria colectiva del pueblo venezolano, garantizando el derecho de las comunidades a participar en el enriquecimiento de los mismos. Asimismo, podrá ejercer, patrocinar e incentivar todas las acciones, actividades y proyectos que sean afines con la historia de Venezuela.

Hugo Chávez Frías, Presidente de la República, Decreto n. 5.643, del 17 de octubre de 2007. 
A partir de entonces, el CNH será el encargado de fijar la orientación y el contenido de la historia nacional y la memoria colectiva de los venezolanos. Varios son los aspectos que caracterizan y componen este relato, en la mayoría de los casos en abierta armonía con el contenido del discurso político del Presidente Chávez. Basta hacer un seguimiento a las muy numerosas referencias sobre la historia de Venezuela, hechas por Chávez, en su amplísimo inventario de discursos, programas de radio o televisión, y los contenidos de las publicaciones y documentos del CNH para identificar la afinidad y uniformidad que existe entre ambos. ${ }^{46}$ Algunos de estos lineamientos pueden resumirse en las siguientes premisas:

- La idealización y reivindicación de los indígenas como expresión de las culturas originarias.

- La condena y satanización del descubrimiento y la conquista como genocidio perpetrado contra los pobladores originarios.

- La reivindicación de las luchas de los esclavizados en la obtención de su libertad.

- El rescate y recuperación de la presencia femenina en la historia, fundamentalmente de las heroínas de la independencia y de las mujeres que tuvieron proximidad afectiva con el Libertador Simón Bolívar.

- Exacerbación de la apología del Libertador, como referente y guía imperecedera de las luchas de los venezolanos por su libertad.

- Atención privilegiada al proceso de la independencia como el cénit de las luchas del pueblo venezolano, estableciendo una relación de continuidad entre la independencia y la revolución bolivariana como el momento en el cual finalmente se pusieron en práctica los objetivos inconclusos de la gesta emancipadora.

- Descalificación y satanización del siglo XX, en particular de las cuatro décadas de la democracia representativa entre 1958 y 1998, antesala de la revolución bolivariana, como un período carente de logros y realizaciones.

${ }^{46}$ Esta comparación forma parte de un proyecto en curso, en el cual se está realizando una selección de los discursos y comentarios sobre la historia de Venezuela hechos por el Presidente Chávez, a fin de cotejar sus contenidos con la información, respecto de estos mismos temas, que se reproduce en Revista Memorias, como también en otros documentos preparados por el Centro Nacional de Historia. 
- Elaboración de una épica de la revolución:

- Presentación de los hechos del Caracazo (27-28 de febrero de 1989), como génesis y justificación del golpe de Estado de 1992.

- Justificación de los golpes de Estado del 4 de febrero y del 27 de noviembre de 1992, presentándolos como una acción cuyo fin era corregir los males y perversiones del régimen democrático. El 4 de febrero fue declarado, posteriormente, Día de la Dignidad Nacional.

- Apología del comandante Chávez y de los logros del gobierno revolucionario.

Todos estos contenidos son difundidos a través de la revista oficial del CNH, que lleva por título Memorias, la cual se plantea como "instrumento para la estrategia rememorizadora" del pueblo venezolano. Dirigida al gran público con tirajes gratuitos de cientos de miles de ejemplares, su objetivo "no es reinterpretar la historia a la medida de un proyecto político, sino hacer una nueva política de la memoria en la que resurjan los actores y circunstancias con perspectivas hacia la construcción de una sociedad justa, equitativa e incluyente". Así está expresado en el portal de presentación de la revista en la página oficial del Centro Nacional de Historia. ${ }^{47}$

Como parte de este objetivo rememorizador y rector del conocimiento histórico, el CNH tuvo especial protagonismo en la conducción de la conmemoración del bicentenario de la independencia, celebración que fue concebida como un proceso que comenzó a fines del siglo XVIII y se mantendría continuo hasta hoy, ya que, de acuerdo al decreto que creó la Comisión del Bicentenario, "nos corresponde como generación, concluir el proceso que se inició en el siglo XIX y que aún no concluye". ${ }^{48}$ En palabras del Dr. Arístides Medina Rubio, primer director del $\mathrm{CNH}$, el bicentenario y el socialismo bolivariano permitirían consolidar la verdadera independencia de Venezuela, mediante la

47 Ver http://cnh.gob.ve/index.php/using-joomla/extensions/components/content-component/article-category-list/82-ultimas-noticias/catalogo-depublicaciones/79-revista-memorias-de-venezuela/.

${ }^{48}$ La Comisión Presidencial para la Conmemoración del Bicentenario de la Independencia de la República Bolivariana de Venezuela fue creada mediante el decreto n. ${ }^{\circ}$ 6015, del 17 de abril de 2008, publicado en la Gaceta Oficial n. ${ }^{\circ} 38912$. 
difusión de tres postulados básicos: la continuidad del proceso de independencia, la participación del pueblo y el protagonismo del Libertador Simón Bolívar. ${ }^{49}$

Como resultado de esta orientación, entre muchas otras actividades, se llevó a cabo el proyecto Memorias de la insurgencia, cuyo resultado fue la edición de un libro en el cual se encuentran reproducidas notas biográficas parciales de varios pardos, esclavos y mujeres que fueron perseguidos y sometidos a juicio por su participación en la independencia, reconstruidas a partir de los expedientes sobre Causas de Infidencia que se encuentran en el Archivo General de la Nación. El objetivo de la publicación fue darles visibilidad a quienes fueron excluidos del relato heroico de la independencia y así responder a los postulados de la Comisión Bicentenario y de los lineamientos establecidos por el $\mathrm{CNH}$. La introducción de la obra cierra con esta afirmación del profesor Luis Pellicer, quien para entonces ocupaba la dirección del Archivo General de la Nación: "Memorias de la insurgencia es una expresión del esfuerzo del gobierno bolivariano por reescribir la historia del pueblo, con el pueblo y para el pueblo". 50

También se elaboraron encartes de difusión masiva sobre distintos hitos y momentos de la gesta independentista, fundamentalmente militares, bajo el título Pueblo admirable, como parte de la conmemoración de los 200 años de la Campaña Admirable, nombre con el que se conoce la campaña realizada por Simón Bolívar en 1813, desde el territorio de la Nueva Granada que culminó exitosamente con su llegada triunfal a Caracas, en agosto de 1813. En la presentación de la colección se reitera la relación de continuidad que existe entre la revolución de la independencia y la revolución bolivariana:

Entendemos la Independencia como un proceso abierto que comenzó hace más de doscientos años, con la gesta heroica del pueblo venezolano y su máximo líder, Simón Bolívar. En este proceso se logra la independencia política y la expulsión del im-

${ }^{49}$ Arístides Medina Rubio, "Bicentenario y socialismo consolidan la verdadera independencia de Venezuela”, El Nacional, 18 de abril de 2008.

50 Luis Pellicer, "Presentación", en Memorias de la insurgencia (Caracas: Centro Nacional de Historia, Archivo General de la Nación, 2011), 8. 
perio español de la tierra nuestraamericana. ${ }^{51}$ El pueblo venezolano continuó luchando durante los siglos XIX y XX por la libertad e igualdad, no obstante, es a partir de 1998, con la Revolución Bolivariana liderada por el comandante Hugo Chávez, que el pueblo ha alcanzado las mayores victorias en la construcción de la Independencia plena. Este año 2013, en el que recordamos la Campaña Admirable y la liberación de Oriente lo haremos llenos de la fuerza telúrica de un pueblo unido y victorioso que como entonces está empeñado, ahora en defender, expandir y consolidar el bien más preciado que hemos reconquistado en la revolución bolivariana: la Independencia Nacional. ${ }^{52}$

El Centro Nacional de Historia, además, tiene a su cargo varios planes de extensión con fines divulgativos: la cátedra de historia insurgente "Federico Brito Figueroa", así como la organización de talleres, cursos de ampliación, formación y conferencias sobre diferentes temas. Contempla también un Plan Nacional de Formación en Historia, cuyo autor es Hugo Chávez Frías y que, bajo la consigna "Hacer memoria es hacer Patria", tiene como objetivos:

- Desarrollar procesos de formación en el ámbito de la historia para impulsar las políticas del Estado Revolucionario Bolivariano destinadas a liberar la conciencia histórica, fortalecer la identidad nacional y nuestroamericana, a fin de construir la Patria Socialista.

51 El término "nuestroamericano" - masculino del similar "nuestraamericana"-, recurrentemente utilizado por Hugo Chávez Frías, está asociado a la necesidad de reivindicar y reforzar la idea de la identidad y especificidad latinoamericanas. Tiene como principales fuentes de inspiración a Simón Bolívar, y su célebre frase "Para nosotros la Patria es América", y a José Martí, y su muy conocido artículo "Nuestra América" publicado en Nueva York, en 1891. Se trata de una instrumentalización política de ambas figuras, lo cual se expresa no sólo en el discurso de Chávez y en los documentos oficiales del gobierno de Venezuela, sino también en muchos otros ámbitos. Un recorrido por internet deja ver los distintos usos y manifestaciones diversas que conlleva la voz "nuestroamericano". Como ejemplo pueden citarse la creación de la "Cátedra Libre del Pensamiento Nuestroamericano Hugo Chávez Frías", en la Universidad de La Plata en Argentina, para "fortalecer la unidad de los países de América Latina"; o la creación del Centro de Estudios Nuestroamericano Chávez-Kirchner, en Venezuela, en mayo de 2016, con el mismo fin.

${ }^{52}$ Ver la presentación de la colección Pueblo Admirable, disponible en

$\mathrm{h}_{\mathrm{ttp}}$ //cnh.gob.ve/index.php/catalogo-de-publicaciones/catalogo-cnh/137colecciones/613-pueblo-admirable. 
- Incentivar la construcción de nuevos paradigmas teóricos, metodológicos y educativos que rompan la visión hegemónica de la historia elitista e impulsen el pensamiento crítico-reflexivo del pueblo venezolano.

- Orientar y apoyar a las instituciones del Estado Revolucionario Bolivariano en la elaboración de actividades relacionadas con la investigación, divulgación y formación de la memoria histórica del pueblo venezolano y nuestroamericano. ${ }^{53}$

Además de este Programa Nacional de Formación Inicial, se crea otro, de adjetivo avanzado, que incluye el grado de maestría y doctorado. En ambos casos, el objetivo es procurar "la descolonización de la memoria histórica de los actores sociales venezolanos". ${ }^{54}$

El propósito, en definitiva, es formar a la generación de relevo que pueda dar continuidad a los contenidos de la nueva historia oficial de la revolución bolivariana, cuya orientación y conducción se encuentran bajo la dirección del Estado, a través del $\mathrm{CNH}$, "ente rector del conocimiento histórico y de la memoria de los venezolanos", como señala el decreto de creación.

\section{LA COLECCIÓN BICENTENARIO}

Dentro de este mismo espíritu formativo, cuyo objetivo es difundir de manera uniforme el relato histórico de la revolución bolivariana, además de las muy diversas actividades que desarrolla el CNH, se llevó a cabo el ambicioso proyecto Colección Bicentenario. Este programa tuvo por fin publicar y difundir, de manera gratuita, manuales escolares para la enseñanza de todas las disciplinas, desde educación básica hasta el ciclo diversificado. Los primeros libros se comenzaron a difundir en el 2011; dos años después se habían distribuido 42 millones de manuales escolares a 6 millones de niños en todo el país.

Tanto su redacción y producción fueron contratadas directamente por el Estado, con la finalidad de adecuar los textos de enseñanza a los

${ }^{53}$ Ver http://cnh.gob.ve/index.php/objetivos-del-plan-nacional-de-formacionen-historia/.

${ }^{54}$ Ver http://cnh.gob.ve/images/PNFA/PNFAH.pdf/. 
lineamientos del Plan Estratégico Simón Bolívar, cuyos fundamentos quedaron expuestos en el Diseño Curricular Bolivariano del año 2007:

- Objetivo: contribuir a refundar la república, para consolidar una sociedad humanista, democrática, protagónica, participativa, multiétnica, pluricultural, plurilingüe e intercultural.

- Inspiración: en las ideas y praxis liberadoras, filosóficas, pedagógicas, políticas, sociales, culturales de ilustres venezolanos y venezolanas, como Simón Rodríguez, Francisco de Miranda, Simón Bolívar, Ezequiel Zamora, Luis Beltrán Prieto Figueroa y Belén San Juan.

- Meta. Superar el modelo educativo basado en los valores del capitalismo: el individualismo, el egoísmo, la intolerancia, el consumismo y la competencia feroz. ${ }^{55}$

Desde que se inició la distribución de los libros, hubo un intenso debate en el cual se expusieron las deficiencias metodológicas de los manuales, haciendo ver que, en su gran mayoría, no alcanzaban el nivel requerido; la información era incompleta; no cumplían con su función bibliográfica; se encontraban ausentes numerosos temas que formaban parte de problemáticas actuales y no siempre había coherencia entre las actividades propuestas y la metodología científica. Se destacó muy especialmente la numerosa y reiterativa presencia de información propagandística sobre el Presidente Chávez y sobre los programas del gobierno bolivariano, lo cual se hacía más visible y recurrente a medida que se avanzaba en los grados de enseñanza. De esta manera, se convertía una importante herramienta didáctica en propaganda política y se contravenía expresamente el derecho a una educación libre y plural, consagrada por la Constitución. ${ }^{56}$

En el caso de las ciencias sociales se hicieron numerosas críticas y observaciones en las que se destacan algunos de los aspectos más relevantes que se advierten en el tratamiento de la historia, como son:

${ }^{55}$ Ministerio del Poder Popular para la Educación, Diseño curricular del sistema educativo bolivariano (Caracas: Ministerio del Poder Popular para la Educación, 2007), 8.

${ }^{56}$ Muchas de estas críticas fueron recogidas en un documento publicado, el 9 de diciembre del 2011, por la Escuela de Educación de la Universidad Católica Andrés Bello. 
- Exaltación de los héroes militares.

- Reiteración del culto a Bolívar y del discurso canónico de la independencia.

- Omisión de períodos históricos y análisis superficial e incompleto de otros.

- Concepción lineal y maniquea de la historia.

- Satanización del período democrático.

- Apología y defensa de los programas, obras y gestión del Presidente Hugo Chávez.

- Ideologización del contenido histórico con fines políticos.

- Deficiencias metodológicas.

- Carencias didácticas.

- Reducido nivel de exigencia. ${ }^{57}$

En relación con el siglo $\mathrm{XX}$, un detallado estudio, realizado por el profesor Tulio Ramírez, deja ver la clara correspondencia entre la valoración política del período previo a 1999 y la justificación de la refundación de la república adelantada por la revolución bolivariana. Así, se describen de manera cronológica los diferentes gobiernos del siglo XX, se juzga negativamente el Pacto de Punto Fijo - acuerdo político al que llegaron los partidos Acción Democrática, Copei y Unión Republicana Democrática para avanzar en la instauración de la democracia en 1958-, se minimizan o descalifican los logros de los gobiernos de la democracia y se glorifica y exalta la lucha armada de los años sesenta. También existe un claro desbalance en el tratamiento del período que se inicia en 1958, respecto a la atención que se presta a los años del gobierno de Hugo Chávez; se establece una comparación maniquea entre los vicios del pasado y las bondades del presente bolivariano, y se presenta a Chávez como continuador de la gesta de Simón Bolívar. ${ }^{58}$

${ }^{57}$ Son especialmente ilustrativos los trabajos de Migdalia Lezama, "Enseñar historia en revolución. Análisis de las propuestas de transformación curricular en Educación emanadas del MPPE (2007-2017)", en Entre el ardid y la epopeya. Uso y abuso de la simbología en el imaginario chavista, de los coordinadores Luis Alberto Buttó y José Alberto Olivar, 81-120 (Caracas: Fundación Negro sobre Blanco Grupo Editorial, 2018); "Uso y abuso de la historia: la historia como justificación ideológica y formadora de militancia política", ponencia presentada en las III Jornadas de Reflexión sobre la Enseñanza de la Historia, que tuvo lugar en la Academia Nacional de la Historia, en Caracas, febrero 2018 (en proceso de publicación).

${ }^{58}$ Tulio Ramírez, "El texto escolar como arma política. Venezuela y su gente. Ciencias sociales, 6to grado", en Investigación y postgrado 27, n. ${ }^{\circ} 1$ (2012). 
Sobre este mismo tema, el profesor Leonardo Carvajal, coordinador de la Asamblea de Educación, si bien reconoció que la gratuidad de los libros era un enorme alivio para el bolsillo de los padres, también manifestó su rechazo a que se pretendiera ideologizar la educación: "No puede haber una historia que sea chavista porque no es científico y la historia debe mostrar logros, debilidades y fortalezas de cada uno de los gobiernos". 59

La ministra del Poder Popular para la Educación, profesora Maryan Hanson, frente a las críticas que se hicieron sobre la colección, respondió que, desde su punto de vista, los manuales de la Colección Bicentenario contribuían al pensamiento crítico, analítico y creativo para la transformación de la realidad. En relación con las observaciones relativas a la presencia recurrente de la figura del Presidente Chávez, dio a conocer su parecer en una rueda de prensa realizada el 26 de noviembre de 2013. Sus palabras fueron: "Sí, aparece el Comandante Eterno porque es la historia inmediata y no tenemos por qué negarla". ${ }^{60}$

Por su parte, algunos de los docentes que estuvieron a cargo de la coordinación y redacción de los libros de ciencias sociales expresaron su apoyo irrestricto al contenido de los manuales, así como a su orientación ideológica, tal como se desprende de una entrevista, realizada en septiembre del 2013, a la profesora América Bracho, coordinadora del área. En su declaración explicó que la idea de hacer los libros se le ocurrió en una oportunidad que estaba viendo a Chávez por televisión. De allí surgió la realización del proyecto editorial de la educación bolivariana cuyo soporte filosófico fue El árbol de las tres raíces, uno de los primeros documentos escritos por Chávez para exponer su proyecto revolucionario.

La orientación de los libros, insiste Bracho, es "liberadora". Se busca la "libertad de pensamiento" y el "pensamiento crítico"; el propósito es enseñar "la verdad", diciendo lo que los otros libros omiten, lo que no les conviene. En su concepto, la educación es un acto político e ideológico. Ésa es, pues, la premisa que guía la orientación y conte-

${ }^{59}$ Leonardo Carvajal, "Los libros de ciencias sociales de primaria: muy positivos pero con perversiones ideológicas", en Política e ideología en los libros de texto. La Colección Bicentenario ante la crítica, de Marta Aquirre, Tulio Ramírez, Leonardo Carvajal y Luis Ugalde (Caracas: CERPE-UCAB, 2015), 17.

60 Ver http://fundabit.gob.ve/noticias-del-ano-2013/noviembre/589-la-coleccion-bicentenario-es-sinonimo-de-educacion-liberadora/. Consultado 7/11/2014. 
nidos de los libros. No comparte las observaciones hechas por algunos críticos, según las cuales están presentes tergiversaciones y omisiones históricas. Frente a un Cipriano Castro presentado anteriormente como dictador, se ofrece ahora un Presidente nacionalista; a los Presidentes de la democracia se les reconocen sus obras públicas, pero se dicen sus errores. Todo lo que se encuentra en los textos "es irrebatible": se trata de "la verdad histórica", afirma Bracho de manera categórica. ${ }^{61}$

El relato no admite fisuras, hay una orientación única que se reproduce a través de los distintos órganos del Estado, en perfecta correspondencia con el discurso del jefe del ejecutivo, a fin de ofrecer una sola lectura del pasado cuya finalidad, como bien lo ha expresado el historiador Manuel Caballero, se corresponde claramente con una orientación de corte totalitario:

(...) lo característico del totalitarismo proviene de la voluntad de imponer una ideología oficial, única y obligatoria al conjunto de la sociedad. No para explicar la historia a la luz de una concepción particular, sino para hacerla entrar a la fuerza en un esquema inamovible y dogmático. ${ }^{62}$

\section{EL LEGADO DE CHÁVEZ Y EL GOBIERNO DE NICOLÁS MADURO}

Esta misma vocación totalitaria, que se ha manifestado en la construcción y difusión de un discurso único sobre el pasado de los venezolanos, se ha expresado también en otra práctica común a los totalitarismos: el culto a la personalidad de quien se erige y se presenta como el gran conductor y guía de los destinos de la nación.

El culto a Chávez, si bien comienza en vida del comandante, propiciado por él mismo y afianzado en su carisma y popularidad, se exacerba y se extiende como política de Estado durante el gobierno de Nicolás Maduro, convirtiéndose en uno de los recursos fundamentales de legitimación política del nuevo Presidente, al presentarse como el continuador y protector del legado de Chávez, quien, además, lo designó a él como su sucesor.

${ }^{61}$ Ver http://www.correodelorinoco.gob.ve/nacionales/textos-coleccion-bicentenario-defienden-libertad-pensamiento/.

${ }^{62}$ Manuel Caballero, Revolución, reacción y falsificación, 209. 
En una de sus últimas alocuciones públicas, luego de haber sido reelegido en las elecciones del 6 de diciembre de 2012, Hugo Chávez se dirigió en cadena nacional al país y designó a Nicolás Maduro para que fuese el próximo Presidente:

Mi opinión firme, plena como la luna llena, irrevocable, absoluta, total es que en un escenario que obligara a convocar de nuevo a elecciones presidenciales ustedes elijan a Nicolás Maduro como Presidente de la República Bolivariana de Venezuela. Yo se los pido de corazón.

Al ungir a Maduro como candidato presidencial y futuro Presidente de Venezuela de manera pública, como una decisión suya "total y absoluta" y sin ningún tipo de consultas, evitaba las confrontaciones que inevitablemente había suscitado en el seno del PSUV la sucesión de Chávez, incluso antes de su fallecimiento. El anuncio, por cierto, tuvo los efectos esperados.

Uno de los momentos culminantes de la apoteosis y deificación de Chávez fue, sin duda, el prolongado y concurridísimo funeral, el cual se extendió por varios días, hasta que finalmente sus restos fueron conducidos a El Cuartel de la Montaña, su última morada, un mausoleo dedicado expresamente a Chávez, que fue concluido en tiempo récord, remodelando las instalaciones de la antigua Academia Militar, levantada en tiempos del general Cipriano Castro, convertida posteriormente en sede del Museo Militar. Este lugar tuvo un sentido simbólico un tanto peculiar, ya que fue desde allí que el comandante Chávez dirigió su fallido golpe militar del 4 de febrero de 1992. Este mausoleo, desde su inauguración en marzo del 2013, es sostenido con presupuesto del Estado y se conserva abierto al público. La tumba cuenta con una guardia de honor permanente igual a la que le rinde honores a Simón Bolívar en el Panteón Nacional; se ha dispuesto igualmente un ceremonial diario de cambios de guardia que incluye un disparo de artillería, todos los días a las 3:15 de la tarde, para recordar la hora en que dejó de existir el "Comandante Eterno", como se lo llama desde entonces.

Son numerosas y elocuentes las manifestaciones del culto a Chávez que acompañan lo que ha sido la gestión de Maduro. En representativos edificios de la administración pública están visiblemente colocadas las imágenes de Chávez y Maduro, acompañadas del "nuevo" 
rostro de Simón Bolívar y, en su exterior, es común que se coloquen los ojos de Chávez en actitud vigilante. Esta misma práctica se advierte en todo el país, en vallas, muros y lugares visibles, incluyendo espacios que forman parte del patrimonio artístico y arquitectónico de la nación, como son las escaleras de El Calvario, una obra construida en el siglo XIX, en tiempos del general Antonio Guzmán Blanco. También los ojos y la firma de Chávez están a la vista en las paredes exteriores de las viviendas de interés social que, bajo el programa Misión Vivienda, se comenzaron a construir durante el gobierno de Chávez y se continúan bajo la administración de Maduro.

Junto a los ojos de Chávez, en tiempos más recientes, se ha extendido el uso de un cartel con el siguiente anuncio "Aquí no se habla mal de Chávez”. La frase fue acuñada por Diosdado Cabello (en su programa de televisión Con el mazo dando), figura de primera línea del PSUV, quien ha ocupado importantes posiciones públicas en los gobiernos de Chávez y Maduro, y actualmente preside la nueva Asamblea Constituyente. Este cartel se encuentra de manera visible en todas las oficinas de la administración pública, en los despachos ministeriales, notarías, taquillas de atención al público, gobernaciones, alcaldías, etcétera, en una clara e inequívoca manifestación de intolerancia, intimidación y de abuso de poder.

De este empeño en mantener presente el legado de Chávez, como padre fundador de la revolución, también ha formado parte la erección de numerosas estatuas ubicadas en diferentes estados: en Barinas, Miranda, Nueva Esparta, Vargas, Guárico, Apure y Bolívar. En la mayoría de los casos se encuentran fuertemente custodiadas, a fin de evitar que sean violentadas o derribadas, como ya ha ocurrido en Barinas — ciudad natal del comandante-, en Margarita, Guarenas y en otros lugares del país.

Son igualmente numerosas las vallas de propaganda que presentan las imágenes de Chávez y Maduro, a fin de destacar la continuidad entre uno y otro, lo cual formó parte de su última campaña electoral el pasado mes de mayo, presentándose bajo la consigna "Juntos podemos más" o "Juntos todo es posible".

Se trata, sin duda, de una práctica cuya carga política y simbólica es a todas luces indicadora del propósito mitificador de Chávez que acompaña a la revolución bolivariana, bajo la conducción del Presidente Nicolás Maduro y una orientación que mantiene el modelo totalitario presente en el uso abusivo de la historia, no sólo para justificar y legiti- 
mar la revolución, sino, muy especialmente, para establecer un discurso ideológico, único e inamovible sobre el pasado de los venezolanos.

La novela 1984, de George Orwell, seguramente es uno de los relatos más estremecedores y representativos de lo que puede llegar a ser la expresión perversa del uso del pasado como práctica totalitaria desde el poder. Dos breves fragmentos son ilustrativos de las experiencias a las cuales se enfrenta Winston Smith, el protagonista de la novela:

En cada descansillo, frente a la puerta del ascensor, el cartelón del enorme rostro miraba desde el muro. Era uno de esos dibujos realizados de tal manera que los ojos le siguen a uno adondequiera que esté. EL GRAN HERMANO TE VIGILA, decían las letras al pie.

O este otro:

Y si todos los demás aceptaban la mentira que impuso el Partido, si todos los testimonios decían lo mismo, entonces la mentira pasaba a la Historia y se convertía en verdad. "El que controla el pasado - decía el eslogan del partido - controla también el futuro. El que controla el presente controla el pasado".

El gran drama de lo que sucede en Venezuela es que no se trata de un relato de ficción como la novela de Orwell, sino de una aplastante realidad a la cual nos enfrentamos los venezolanos a diario. Es desde esta vivencia cotidiana que, siguiendo al maestro Iggers, muchos historiadores venezolanos, entre quienes me cuento, seguimos empeñados en ser fieles al ethos profesional del historiador, estudiando, analizando y desnudando críticamente la instrumentalización del pasado que con tanta persistencia se ha mantenido presente en los gobiernos de Chávez y Maduro.

\section{BIBLIOGRAFÍA}

Almarza, Ángel. "Dos siglos de historia mal contadas". En El relato invariable. Independencia, mito y nación, coordinado por Inés Quintero. 125-154. Caracas: Editorial Alfa, 2011.

Altez, Rogelio. "Historia sin memoria: la cotidiana recurrencia de eventos desastrosos en el Estado Vargas-Venezuela". Revista Geográfica Venezolana, n. ${ }^{\circ}$ especial (2005): 313-342. 
. "Independencia, mito genésico y memoria esclerotizada". En El relato invariable. Independencia, mito y nación, coordinado por Inés Quintero. 1956. Caracas: Editorial Alfa, 2011.

- "Más allá del desastre. Reproducción de la vulnerabilidad en el Estado Vargas (Venezuela)". Cahiers des Amériques Latines 65, n. 3 (2010): 123143.

Arenas, Nelly \& Luis Gómez Calcaño. El imaginario redentor de la Revolución de Octubre a la Quinta República. Caracas: Cendes UCV, 2000.

Asamblea Nacional. Diario de Debates, 17 de enero de 2006.

—. "Exposición de motivos de la reforma de la ley bandera, escudo e himno nacionales". Diario de Debates, enero-febrero de 2006.

Barrera Tyszka, Alberto. "El evangelio según Chávez". El Nacional, 21 de noviembre de 1999.

Buttó, Luis Alberto \& José Alberto Olivar. Entre el ardid y la epopeya. Uso y abuso de la simbología en el imaginario chavista. Caracas: Fundación Negro sobre Blanco Grupo Editorial, 2018.

Caballero, Manuel. Contra la abolición de la historia. Caracas: Editorial Alfa, 2008.

_. "Los enemigos de Bolívar". El Universal, 22 de noviembre de 1999.

- Por qué no soy bolivariano. Una reflexión antipatriótica. Caracas: Alfadil Ediciones, 2006.

- Revolución, reacción y falsificación. Caracas: Alfadil Ediciones, 2002.

Carrera Damas, Germán. El bolivarianismo-militarismo, una ideología de reemplazo. Caracas: Editorial Alfa, 2011.

—. El culto a Bolívar. Esbozo para una historia de las ideas en Venezuela. Caracas: Ediciones de la Biblioteca de la Universidad Central de Venezuela, 1969.

Carvajal, Leonardo. "Los libros de ciencias sociales de primaria: muy positivos pero con perversiones ideológicas". En Política e ideología en los libros de texto. La Colección Bicentenario ante la crítica, de Marta Aquirre, Tulio Ramírez, Leonardo Carvajal \& Luis Ugalde, s.j., Caracas: CERPE-UCAB, 2015.

Castro Leiva, Luis. De la patria boba a la teología bolivariana. Ensayos de historia intelectual. Caracas: Monte Ávila Editores Latinoamericana, 1987.

- Obras completas. Caracas: Universidad Católica Andrés Bello y la Fundación Empresas Polara, 2005-2009.

Chávez Frías, Hugo. Agenda alternativa bolivariana. Caracas: sin editorial, 1996.

. "Discurso de toma de posesión ante el Congreso de la República". Caracas

2 de febrero de 1999. http://todochavez.gob.ve/todochavez/3013-toma-deposesion-del-comandante-presidente-hugo-rafael-chavez-frias/.

—. "Discurso del ciudadano Hugo Rafael Chávez Frías, Presidente de la República”. Diario de Debates, 5 de agosto de 1999. http://todochavez.gob. 
ve/todochavez/3482-intervencion-del-comandante-presidente-hugo-chavezfrias-en-la-asamblea-nacional-constituyente/.

Ideas fundamentales para la Constitución Bolivariana de la V República. Caracas: sin editorial, 1999.

Consalvi, Simón Alberto. "Sin tranquilidad en el sepulcro". El Nacional, 21 noviembre de 1999.

García Soto, Carlos. “¿Cómo fue el proceso constituyente de 1999?”. http:// historico.prodavinci.com/blogs/como-fue-el-proceso-constituyente-de-1999por-carlos-garcia-soto/.

Gómez, Alejandro. "El papel de los intelectuales en la Venezuela de Hugo Chávez: los historiadores a la palestra pública”. L'Ordinaire Latino-Américain 202 (2005): 83-94.

González de Luca, María Elena. "Historia, usos, mitos, demonios y magia revolucionaria". Revista Venezolana de Economía y Ciencias Sociales 11, n. ${ }^{\mathrm{o}}$ 2 (2005): 159-186.

Iggers, Georg. La historiografia del siglo XX. Desde la objetividad cientifica al desafio posmoderno. Santiago: FCE, 2012.

—. "Introductory Remarks to the Panel The Uses and Misuses of History". En Congreso Oslo 2000. http://www.oslo2000.uio.no/program/papers/m3a/m3iggers.pdf/.

Junta General. Libro de Actas de la Junta General de la Academia Nacional de la Historia. 1999.

Krauze, Enrique. El poder y el delirio. Caracas: Editorial Alfa, 2008.

Langue, Frédérique. "De panteones cívicos e imaginarios políticos. Los usos del pasado en la revolución bolivariana”. En Hugo Chávez: una década en el poder, editado por Francesca Ramos Pismataro, Carlos A. Romero \& Hugo Ramírez Arcos. 761-781. Bogotá: Universidad del Rosario/Centro de Estudios Políticos e Internacionales/Observatorio de Venezuela, 2010.

—. "La Independencia de Venezuela. Una historia mitificada y un paradigma heroico". Anuario de Estudios Americanos 66, n. 2 (2009): 245-276.

—. "“Levántate Simón, que no es tiempo de morir'. Reinvención del Libertador e historia oficial en Venezuela". Araucaria Revista Iberoamericana de Filosofia, Política y Humanidades 25 (2011).

—_. "Usos del pasado y guerra de las memorias en la Venezuela de la 'Segunda Independencia"”. Polis 34 (2013).

Lezama, Migdalia. "Enseñar historia en revolución. Análisis de las propuestas de transformación curricular en Educación emanadas del MPPE (2007-2017)". En Entre el ardid y la epopeya. Uso y abuso de la simbología en el imaginario chavista, de los coordinadores Luis Alberto Buttó \& José Alberto Olivar, 81120. Caracas: Fundación Negro sobre Blanco Grupo Editorial, 2018.

_ - "Uso y abuso de la historia: la historia como justificación ideológica y formadora de militancia política". Ponencia presentada en las III Jornadas de Reflexión sobre la Enseñanza de la Historia. 2018. 
Martínez Garnica, Armando. "La nacionalización de los símbolos patrios”. En La República de Colombia 1819-1830. El legado de una experiencia nacional, trabajo del postdoctorado en historia, Universidad Andina Simón Bolívar. Quito: 2015. Inédito.

Medina Rubio, Arístides. "Bicentenario y socialismo consolidad la verdadera independencia de Venezuela". El Nacional, 18 de abril de 2008.

Ministerio del Poder Popular para la Educación. Diseño curricular del sistema educativo bolivariano. Caracas: Ministerio del Poder Popular para la Educación, 2007.

Pellicer, Luis. "Presentación”. En Memorias de la Insurgencia. Caracas: Centro Nacional de Historia, Archivo General de la Nación, 2011.

Pino Iturrieta, Elías. El divino Bolivar. Caracas: Alfadil Ediciones, 2006.

. Positivismo y gomecismo. Caracas: Facultad de Humanidades y Educación, Instituto de Estudios Hispanoamericanos, 1978.

—_. "La tropelía de la República Bolivariana". El Universal, 16 de noviembre de 1999: 1-4.

Pinto, Julio. "Cien años de propuestas y combates. La historiografía chilena del siglo XX". En Cien años de propuestas y combates. La historiografía chilena del siglo XX, de Julio Pinto \& María Luna Argudín. 21-114. México: Universidad Autónoma Metropolitana, 2006.

Quintero, Inés (coordinadora). El relato invariable. Independencia, mito y nación. Caracas: Editorial Alfa, 2011.

—. "Bolívar dictador, Bolívar revolucionario". En El Bolívar de Marx. 27-47. Caracas: Editorial Alfa, 2007.

Ramírez, Tulio. "El texto escolar como arma política. Venezuela y su gente. Ciencias sociales, 6to grado". En Investigación y postgrado 27, n. ${ }^{\circ} 1$ (2012).

Straka, Tomás. La épica del desencanto. Bolivarianismo, historiografía y política. Caracas: Editorial Alfa, 2009.

Torres, Ana Teresa. La herencia de la tribu. Del mito de la Independencia a la Revolución Bolivariana. Caracas: Editorial Alfa, 2009.

VV.AA. "La Academia Nacional de la Historia y los símbolos patrios". El Nacional, 11 de febrero de 2006.

“Juntos por el NO”. El Universal, 1 de diciembre de 1999. EP 